\title{
Vigorous Knowledge Management in the Dutch Public Sector
}

\author{
Daphne de Groot \\ Ministry of the Interior and Kingdom Relations \\ Daphne.Groot@minbzk.nl
}

\begin{abstract}
Knowledge has become a critical asset. Organisations which take good care of their knowledge resources have a competitive advantage over those that do not - a principal that applies in government organisations no less than in commercial. Within society as a whole, government is also a competitor - for example, on the labour market or with national non-government organisations (NGOs) over policy. Accordingly, government also needs to be careful to manage its knowledge effectively. This study discusses the ways in which Dutch central government has tried to come to grips with the concept of knowledge management in the public sector.
\end{abstract}

\section{Introduction}

The increasing complexity of society due to information and communication technology (ICT), globalisation, integration of products (e.g. multi-media) and services (e.g. bank assurance) and the proliferation of specialist professions and products has made ours a knowledge-based world. According to the Ministry of Economics, indeed, the Netherlands is 'rapidly developing into a knowledge-intensive economy. An increasingly large part of our income has to be earned by supplying knowledge-intensive services and by manufacturing and marketing knowledgeintensive products. "Knowledge" is becoming a key production factor' (Ministry of Economics, 2000).

Where once data, and later information, were the most important factors in managing an organisation, now the key control mechanism is knowledge (Weggeman, 1997; Davenport and Prusak, 1998). And yet the concept of knowledge management is not a concept which directly fits the essence of public administration. Rather, knowledge management is a concept imported from the trade and industry, and governed by principals such as effectiveness, economic efficiency and output. Knowledge management is therefore ultimately aimed at optimising knowledge within the organisation to increase productivity and profit.

In the public sector, by contrast, even though the principals of efficiency and effectiveness are well established, knowledge management must answer to different priorities (Van Duivenbode and Lips; in Van Duivenbode, Lips and Frissen (eds.), 1999). Profit and money-making are not prevalent in public management. Rather, concepts like justice and equality, legitimacy and responsibility predominate.

The original version of this chapter was revised: The copyright line was incorrect. This has been corrected. The Erratum to this chapter is available at DOI: 10.1007/978-3-540-44836-5_33

M.A. Wimmer (Ed.): KMGov 2003, LNAI 2645, pp. 94-99, 2003.

(C) Springer-Verlag Berlin Heidelberg 2003 


\section{Knowledge Management in the Public Sector}

Due to the complexity of the policy-making process, the information on which it depends comes partially from within the organisation itself, but also in a large part from outside. Civil organisations, special interest groups, universities and research institutions all contribute knowledge out of which policy is developed. The problem is that in a complex society vast quantities of knowledge are available, but not always the right knowledge, inside as well as outside the governmental organisation. From the internal perspective, this superabundance is a liability because knowledge resides above all inside people's heads and therefore in large governmental organisations it is hard to access people's knowledge. The result of this is, that:

- (Crucial) knowledge is available only to small group of people.

- Knowledge is often not available to the people who need certain knowledge.

- Employees are overloaded with irrelevant information.

To handle these problems different government departments have attempted to develop knowledge management instruments. As these attempts make clear, knowledge management has become an important controlling device within the public sector. The Ministry of the Interior and Kingdom Relations, therefore, has tried to understand the possibilities of knowledge management for central government.

\section{Vigorous Knowledge Management}

The Ministry of the Interior and Kingdom Relations has a coordinating role within the public sector in the Netherlands. It consequently plays an important part in constructing a governmental vision of knowledge management. Without this broadly based vision the outlines of any knowledge management system are likely to be fragmented, leading to an insufficiently comprehensive application of the concept to government. The coordinating role of the Ministry of the Interior and Kingdom Relations with respect to knowledge management in the Netherlands can be defined according to three imperatives:

1. Developing a policy vision, which accommodate knowledge management initiatives for the entire central government.

2. Taking the lead by creating a framework of knowledge management for the entire central government while allowing departments to develop their own individual knowledge initiatives.

3. Monitoring development across central government and letting 'a hundred flowers blossom' without imposing a single rigid definition of the concept.

In their article about knowledge management in the public sector, Van Duivenbode and Lips (in Van Duivenbode et al., 1999) conclude that the public sector needs 'diversity in its approach to the concept knowledge management, with attention focused on the culture of the organisation, the routines of the organisation and the environment of the organisation, as well the organisation itself, the employees as the role of ICT as a facilitating instrument of knowledge management (p. 334, translation by the author). According to Van Duivenbode and Lips, this means that knowledge management in the public sector requires a multiform approach. 
The Ministry of the Interior and Kingdom Relations came to its position on government knowledge management by taking the lead in developing a framework in which knowledge management initiatives could be pursued. To create this framework, the Ministry organised a conference in which several other ministries presented their initiatives in the knowledge management arena. It emerged that several different approaches to knowledge management were being pursued simultaneously in central government, leading to considerable misunderstanding. A second conference was therefore organised in which task forces were formed around specific issues, like resource management, organisational structure and information and communication technology. But rather than seeing these issues as the focal points around which knowledge management should be organised, it was argued that knowledge management should instead be a combination of people, organisation and technique.

In order to get a more public administration perspective on where the focus of knowledge management should lie in the public sector in the Netherlands, the Ministry of the Interior and Kingdom Relations defined a research mandate to investigate the feasibility of a 'conceptual' knowledge management framework, in which the different components of the public sector could be positioned. Based on the work of Van Duivenbode, Lips and Frissen (1999), it was felt that there was a need for a more flexible, multiform concept, especially for central government - but grounded in a recognisable and practical framework.

Based on interviews with key players in the field and approximately 40 working studies about knowledge management from ministries, a conceptual framework was created. The creation of the framework is a crucial step in structuring the understanding of the application of knowledge management in general and specifically in the public sector.

Table 1. The framework consists of the following configurations

Responsive knowledge management

Motive: business-related motives

Definition of knowledge: informative

knowledge

Definition of management: business

management

Model: business-related model

Scope: hidden projects

Approach: strengthening of knowledge

management

Instruments: responsive instruments

Integrative knowledge management

Motive: strategic motives

Definition of knowledge: experience-based

knowledge knowledge

Definition of management:

strategic management

Model: strategic model

Scope: massive projects

Approach: strengthening of

knowledge sharing

Instruments: integrative instruments
Reflexive knowledge management

Motive: policy motives

Definition of knowledge: interactive

knowledge

Definition of management: policy

management

Model: policy model

Scope: high-profile projects

Approach: strengthening of

knowledge use

Instruments: reflexive instruments

Innovative knowledge management

Motive: administrative motives

Definition of knowledge: new

Definition of management: administrative management

Model: administrative model

Scope: radical projects

Approach: strengthening of

knowledge creation

Instruments: innovative instruments

In short, the different knowledge management configurations contribute to the following goals: 
- Responsive knowledge management, used in order to optimise knowledge management with a view to the ideal of the digital organisation.

- Reflexive knowledge management, used in order to strengthen knowledge use with a view to the ideal of the professional organisation.

- Integrative knowledge management, used in order to promote knowledge sharing with a view to the ideal of intelligent organisation forms.

- Innovative knowledge management, used in order to increase knowledge creation with a view to the ideal of flexible organisation forms.

The conceptual framework offers an understanding of how knowledge can work. To stimulate this process of recognition and determination, an initial proposal for a diagnostic and intervention instrument is sketched below (Ministry of the Interior and Kingdom Relations, 2001)

Step 1 Assess the nature of the setting applicable to the government ministry, or rather ministry units, by first assessing the nature of the knowledge base: how unequivocal is this knowledge base? Are issues measurable: can facts be gathered? Are the facts controversial: is it clear what facts are important? Can the significance of the facts be determined: are the facts selfexplanatory?

Step 2 Assess the nature of the setting by evaluating the stability of issues: is the existing setting under discussion? Do the issues attract much political, parliamentary and/or media attention? Is there little time for administrative action? Are the existing policy structures under discussion?

Check 1: In taking both these steps consider the question of whether the setting in which the ministry or the unit finds itself is a 'split' setting. It may be that specific issues or knowledge field belong to different settings. The wider the knowledge management horizon and the more ministry units covered, the more likely this is.

Check 2: In taking both the above steps consider whether the knowledge base and/or issue stability will be subject to change in the short or medium term.

Step 3 Combine steps 1 and 2 and identify the type settings (a quiet setting: a setting in which it is relatively clear what the policy players have to do and in which there is sufficient time to work on the issues; an unquiet setting: a setting in which the knowledge field is clear, but in which the issues are or become unstable, thereby necessitating rapid action; an expert setting: a setting in which experts call the shots because the issues are complex and expert views differ; and/or an open setting: a setting in which much is unclear at any given time, experts are in disagreement and existing policy structures are under discussion - possibly at a fundamental level).

Step 4 Choose the type(s) of knowledge management applicable to the setting(s), that is responsive, reflexive, integrative or innovative knowledge management. Choose the correct motive, definitions, models, scope, introduce different, appropriate knowledge management projects. 
Step 5 Create a project structure or team(s) or determine the duties of existing directorates or departments in accordance with the type of scope, so that the project is given organisational legitimacy.

Steps 6 Work on the implementation of the project or projects from the correct organisational embedding. The more open the setting the more 'force' will be necessary (in other words, more documents, more meetings and so forth). In quieter settings this can be done much more unobtrusively.

Check 3: Monitor whether the nature of the setting changes and, if so, go back to step 1.

\section{Experiences with the Conceptual Framework}

If we examine the usefulness of the managerial diagnostic and intervention instrument in implementing knowledge management in central government, we see that the framework on which the instrument is based is very useful, but the method of implementing differs from the steps described earlier. Two ministries have used different approaches to applying the framework. The Ministry of the Interior has focused primarily on the outline of the responsive knowledge management and the Ministry of Social Affairs and Employment initially filled in the four configurations on behalf of their internal positioning and definition.

\subsection{Ministry of the Interior and Kingdom Relations}

The focus of the Ministry of the Interior and Kingdom Relations has been on the issue of responsive knowledge management. The Ministry sees it as its main task to enlarge the responsive capacity of the public sector, for which legal knowledge is the most crucial element. Policy is often based on legal functions, such as laws, (international) treaties, etc. The Ministry has conducted a research project, therefore, to find ways in which legal knowledge can be made more accessible, usable and deliverable (O\&I Management, 2003). The study concluded that it is hard to store legal information in such a way that it can be used comprehensively by policy makers with its original context intact. Even 'hard' explicit information like legal information can only be understood in its proper context. The researchers therefore proposed a central implementation of legal knowledge management from a shared services point of view. That means that the technical management would be organized centrally, but the content managed locally.

In conclusion, just to enlarge the responsive capacity of government by making legal information accessible is not enough. Responsive knowledge needs a human, organizational and contextual perspective. 


\subsection{Ministry of Social Affairs and Employment}

The Ministry of Social Affairs and Employment used the conceptual framework to gain insight into the task of the Department Research and Development. In a study (Ministry of Social Affairs and Employment, 2002) for each of the configurations priorities and functions were identified. For each of the configurations instruments were then defined for each target group and each main task. No attempts were made to implement the framework according to steps of the diagnostic and intervention instrument to effectuate it in policy-making. Unfortunately however, before the implementation of the framework could be effected, the Department Research and Development was dissolved with no real use of the instruments having been made.

\section{Conclusion}

Due to the diverse character of the public sector, effective knowledge management demands the development of a multiform conceptual framework that can be employed by ministries to design their knowledge function. The framework as presented in the paper proofed its significance by helping to understand knowledge management in the public sector. The diagnostic and intervention instrument, in which issues and facts dictate the setting, has not worked; the managerial approach in a policy environment has not proven its value yet.

\section{References}

1. Ministry of Economic Affairs. Pilot project: Balancing with knowledge. Department of General Technology Policy. The Hague, June 1999

2. Ministry of the Interior and Kingdom Relations. Vigorous knowledge management. Department of Public Information Policy, The Hague, 2001

3. Ministry of Social Affairs and Employment. Knowledge management in research and development. Department of Research and Development, The Hague, 2002

4. Davenport, T.H. and Prusak, L. Working knowledge. How organizations manage what they know. Harvard Business School Press, 1998

5. O\&I Management partners. Juridisch kennismanagement voor de Rijksoverheid. Department of Public Information Policy, The Hague, 2003 (in Dutch)

6. Van Duivenbode, Lips and Frissen (eds.) Kennismanagement in de Publieke Sector, Elsevier bedrijfsinformatie bv, The Hague, 1999 (in Dutch)

7. Weggeman, M., Kennismanagement: Inrichting en besturing van kennisintensieve organisaties. Scriptum management, Schiedam, 1997 (in Dutch) 